\title{
Publisher Correction: Purification, Biochemical Characterization, and Facile Immobilization of Laccase from Sphingobacterium ksn-11 and its Application in Transformation of Diclofenac
}

\author{
Kulkarni S. Neelkant ${ }^{1} \cdot$ Kumar Shankar $^{1}$ • Senigala K. Jayalakshmi ${ }^{2}$ • \\ Kuruba Sreeramulu ${ }^{1}$ \\ Published online: 17July 2020 \\ C Springer Science+Business Media, LLC, part of Springer Nature 2020
}

Publisher Correction: Applied Biochemistry and Biotechnology https://doi.org/10.1007/s12010-020-03371-1

The original version of this article unfortunately contained a mistake in the equation under the "Immobilized Laccase Activity and its Storage Stability" section. The equation should be presented as:

$$
\text { Activity recovery }(\%)=\frac{\text { observed activity } \times 100}{\text { starting activity }}
$$

The original article has been corrected.

Publisher's Note Springer Nature remains neutral with regard to jurisdictional claims in published maps and institutional affiliations.

The online version of the original article can be found at https://doi.org/10.1007/s12010-020-03371-1

Kuruba Sreeramulu

ksramu@rediffmail.com; ksramu@gug.ac.in

Kulkarni S. Neelkant

Neelkant.biochemistry@gug.ac.in

Kumar Shankar

Shankarmatpathi.biochemistry@gug.ac.in

Senigala K. Jayalakshmi

skj164@rediffmail.com

1 Department of Biochemistry, Gulbarga University, Kalaburagi 585106, India

2 College of Agriculture, University of Agricultural Sciences-Raichur, Kalaburagi 585103, India 